\title{
Nuclear factor-kappa B signaling pathways and parasitic infections: An overview
}

Review

Article

\author{
Samar M Alhusseiny, Samar N El-Beshbishi
}

Department of Medical Parasitology, Faculty of Medicine, Mansoura University, Mansoura

35516- Egypt

\begin{abstract}
Host nuclear factor-kappa B (NF- $\mathrm{BB})$ transcription factor plays a pivotal role in innate immunity and resistance to infection. It induces the expression of several genes that encode pro-inflammatory cytokines. It also participates in regulating the differentiation and survival of innate immune cells and lymphocytes. Infection of host cells with pathogens usually activates host NF- $\mathrm{BB}$ signaling pathways. The majority of parasites evolved diverse protective mechanisms against NF- $\kappa B$ activity to shield their continued existence. Herein, we present brief insights into NF- $\mathrm{BB}$ signaling pathways, activators and inhibitors, and the main subsequent events following protozoan and helminthic infections in vitro, as well as in vivo either in experimental models, or in humans. Understanding the underlying mechanisms of NF- $\mathrm{kB}$ activation and inhibition may be of great help as a therapeutic strategy against different parasitic infections.
\end{abstract}

Keywords: helminths; innate immunity; novel drugs; nuclear factor-kappa B; pro-inflammatory cytokines; protozoa; toll-like receptors.

Received: 18 August, 2021, Accepted: 10 October, 2021.

Corresponding Author: Samar N. El-Beshbishi, Tel.: +20 1224142147, E-mail: selbeshbishi@mans.edu.eg

Print ISSN: 1687-7942, Online ISSN: 2090-2646, Vol. 14, No. 3, December, 2021.

Abbreviations: DCs: Dendritic cells; ECs: Endothelial cells; ESPs: Excretory-secretory products; IKK: Inhibitor of nuclear factor-

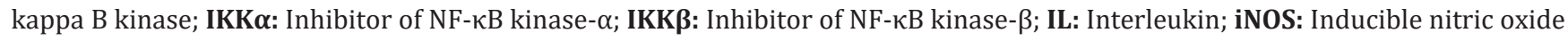

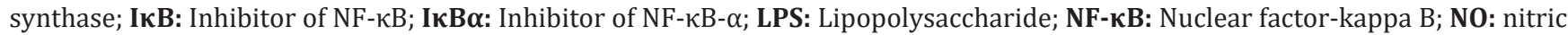
oxide; TLR: Toll-like receptor; TNF- $\alpha$ : Tumor necrosis factor- $\alpha$.

\section{INTRODUCTION}

Host responses to infection are generally categorized into innate and adaptive immune responses. Foreign pathogens stimulate the host immune response with associated host and pathogen cascades. Consequently, signal transduction events induce changes in gene expression, followed by release of cytokines and other factors such as inflammatory mediators and chemokines that mediate recognition ${ }^{[1]}$.

Induced transcriptional changes are controlled by $N F-\kappa B$ signaling. Notably, NF- $\kappa B$ was first identified in active $B$ cells by its binding affinity to immunoglobulin $\kappa$ light-chain gene transcriptional enhancer ${ }^{[2]}$. Besides, $\mathrm{NF}-\mathrm{\kappa B}$ serves as dominant modulator of immunoinflammatory responses. Members of $\mathrm{NF}-\kappa \mathrm{B}$ are usually found in the cytoplasm in a dormant state. Following stimulation of the innate immune receptors, $\mathrm{NF}-\kappa \mathrm{B}$ becomes activated for nuclear translocation and activation of gene transcription ${ }^{[3]}$. Its signaling activity is essential for utmost transcription of many inflammatory mediators, chemokines, and cytokines in immune cells. Suppressing the activity of NF- $\kappa B$ signaling can be advantageous in controlling several disease inflammatory processes, including parasitic infections that manipulate $\mathrm{NF}-\mathrm{\kappa B}$ in different ways. However, constant NF- $\mathrm{BB}$ inhibition can be associated with intense adverse effects. Therefore, interpretation of the full dynamics of the pathological consequences of NF- $\kappa \mathrm{B}$ activation in different diseases is fundamental ${ }^{[4,5]}$.

\section{Signaling pathways}

Family members of NF- $\kappa$ B include inducible transcription factors that control an enormous array of genes concerned with inflammation and immunity ${ }^{[6]}$. There are five structurally related members; NF- $\mathrm{kB} 1$ (p50), NF-кB2 (p52), RelA (p65), RelB, and c-Rel, that control target genes transcription by binding to $\kappa \mathrm{B}$ enhancer (a peculiar DNA element), as homo- or hetero-dimers ${ }^{[7]}$. Normally, inhibitory proteins are responsible for cytoplasmic sequestration of NF- $\mathrm{KB}$ proteins. These include inhibitor of nuclear factorkappa B (I $\mathrm{B}$ ) family members in addition to related proteins, such as inhibitor of NF- $\kappa B-\alpha(I \kappa B \alpha)$ as the most significant inhibitor. It is worth mentioning that $\mathrm{I} \kappa \mathrm{B} \alpha$ degradation is induced by inhibitor of nuclear factor-kappa B kinase (IKK) complex through sitespecific phosphorylation. It is observed that IKK contains two catalytic subunits: inhibitor of NF- $\kappa B$ kinase- $\alpha$ (IKK $\alpha)$ and inhibitor of NF- $\kappa B$ kinase- $\beta$ (IKK $\beta$ ); besides inhibitor of NF- $\kappa B$ kinase- $\gamma$ (IKK $\gamma$ ), which is a regulatory subunit known as NF- $\mathrm{BB}$ essential modulator (NEMO) ${ }^{[8]}$.

Two main pathways activate NF- $\kappa \mathrm{B}$ signaling; the classical (canonical) and alternative (non-canonical or atypical) pathways (Figure 1). The first is associated 


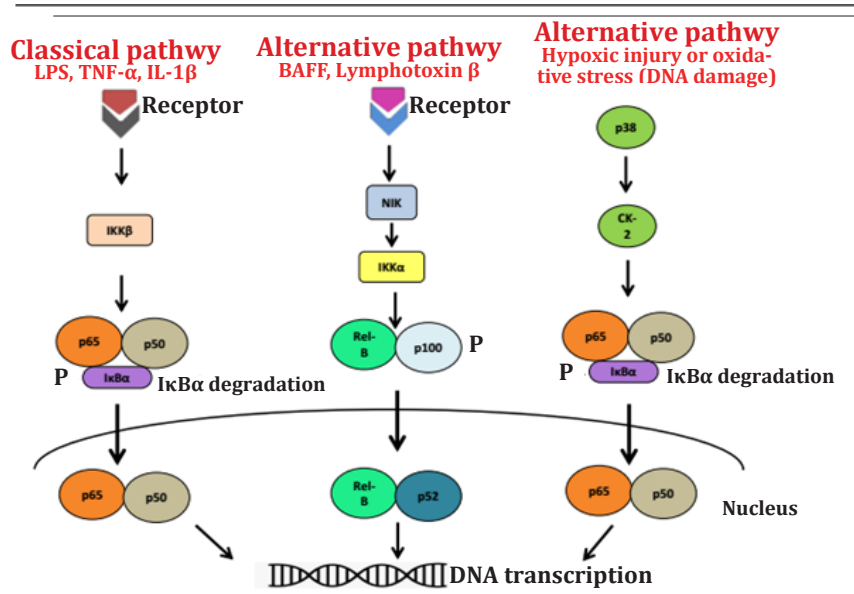

with immune and inflammatory responses, whereas the latter is a secondary signaling pathway concerned with controling adaptive immunity, B cell function, and lymphoid organ development ${ }^{[1]}$. Activators of the classical pathway include lipopolysaccharide (LPS), tumor necrosis factor- $\alpha$ (TNF- $\alpha$ ), or interleukin (IL)-1 $\beta$, that attach to specific receptors. Sequences include IKK $\beta$-mediated phosphorylation of I $\mathrm{I} B \alpha$ that becomes degraded through the proteasome releasing p50/p65 dimers. On the other hand, the alternative pathway is induced by B-cell activating factor (BAFF) or lymphotoxin $\beta$. It includes IKK $\alpha$ activation through NF- $\kappa B$ inducing kinase (NIK), p100 phosphorylation by IKK $\alpha$, and its processing by the proteasome to yield p52. Next steps include liberation of RelB/p52 dimers, nuclear translocation, and triggering specific genes, which are different from the genes controlled by the classical pathway. In the atypical pathway, hypoxic injury or oxidative stress (DNA damage) leads to massive I $\kappa \mathrm{B} \alpha$ phosphorylation via $\mathrm{p} 38$-induced casein kinase-2 (CK-2) and release of p50/p65 dimers ${ }^{[9]}$.

\section{Role of NF- $\kappa B$ signaling in immune response and inflammatory process}

Extensive studies have been conducted on NF- $\kappa B$ signaling pathways owing to its major role in activating plentiful genes implicated in the infection response. Cell surface toll-like receptors (TLRs) expressed via dendritic cells (DCs), mucosal epithelial cells, and macrophages are the main component of the innate immune response that identifies pathogens (cell wall LPS and nucleic acids) ${ }^{[10]}$. Once triggered, all TLRs endorse the NF- $\kappa B$ signaling pathways ${ }^{[11]}$. These NF- $\kappa B$ pathways elicit macrophage inflammatory protein $-1 \alpha$ (MIP-1 $\alpha$ ), pro-inflammatory cytokines (e.g. TNF- $\alpha$, IL-1, and IL-6), besides adhesion molecules such as vascular cell adhesion molecule-1 and E-selectin expression ${ }^{[10]}$. It was reported that E-selectin belongs to cell adhesion molecules that are expressed by cytokines-activated endothelial cells (ECs). It is designated as CD62E, and is recognized to have chief effects during the inflammation response ${ }^{[12]}$. After release, TNF- $\alpha$ and
Fig. 1. Nuclear factor-kappa B signaling pathways. Activators of NF- $\mathrm{KB}$ bind corresponding receptors and activate IKK $\beta$ in the classical pathway and IKK $\alpha$ via NIK in alternative pathway. DNA damage acts through p38 and CK-2. Kinases phosphorylate I $\mathrm{I} B \alpha$, and p100. Active dimers of NF- $\mathrm{KB}$ are released, translocate to the nucleus, and bind DNA to start target genes transcription. Illustrated by Alhusseiny SM.

BAFF: B-cell activating factor; CK-2: Casein kinase-2;

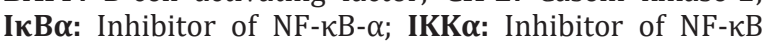
kinase- $\alpha$; IKK $\boldsymbol{\beta}$ : Inhibitor of NF- $\kappa B$ kinase- $\beta$; IL-1 $\boldsymbol{\beta}$ : Interleukin-1 $\beta$; LPS: Lipopolysaccharide; NIK: NF-KB inducing kinase; P: Phosphorylation; TNF- $\alpha$ : Tumour necrosis factor- $\alpha$
IL-1 reactivate NF- $\kappa B$ pathway, with further response augmentation. Moreover, NF- $\kappa \mathrm{B}$ activates $\mathrm{B}$ and $\mathrm{T}$ lymphocytes receptors (co-stimulatory and antigen), besides supporting the survival and differentiation of $B$ cells through B-cell activating factor activity ${ }^{[13]}$.

\section{Inhibition of NF- $\kappa \mathrm{B}$ signaling pathways}

In most cells, activation of NF- $\kappa B$ pathway is usually a temporary process ( $\sim 30-60 \mathrm{~min})$. Persistent NF- $\kappa B$ signaling is inhibited by down-regulation of NF- $\kappa B$ within a feedback loop (negative feedback). The gene that encodes I $\mathrm{B} \alpha$ is provoked by NF- $\kappa \mathrm{B}$, and newlyformed I $\kappa B \alpha$ enters the nucleus, eliminates NF- $\kappa B$ from DNA, and sends the complex again to the cytoplasm. There, NF- $\kappa B$ is retained till further activation ${ }^{[13]}$. Dysregulation of $\mathrm{NF}-\kappa \mathrm{B}$ is associated with diverse health problems, e.g. multiple sclerosis, cerebral stroke, Alzheimer's disease, atherosclerosis, bronchial asthma, diabetes mellitus, viral infections, and genetic disorders. Proper control of NF- $\kappa B$ signaling through pharmacological or genetic therapies represents a novel strategy for the management of NF- $\mathrm{BB}$ related disorders $^{[14]}$.

Interestingly, $\mathrm{NF}-\kappa \mathrm{B}$ signaling pathways can be prevented through many pharmacological agents that inhibit NF- $\kappa \mathrm{B}$ activity at different levels including:

- Non-steroidal anti-inflammatory drugs (e.g. sodium salicylate and aspirin) act by inhibiting cytokine and endotoxin-induced nuclear translocation of NF- $\kappa \mathrm{B}$ through preventing phosphorylation and proteolysis of $\mathrm{I} \kappa \mathrm{B} \alpha^{[15]}$. Besides, they can serve as IKK inhibitors and act by specifically inhibiting ATP-binding to IKK $\beta$. Consequently, they markedly decrease IKK $\beta$-dependent phosphorylation, and prevent both IKK $\beta$ proteasomal degradation and NF$\kappa \mathrm{B}$ pathway activation ${ }^{[16]}$.

- Steroids (e.g. glucocorticoids) that directly interact with NF- $\kappa \mathrm{B}$ and activator protein-1 (AP-1), and produce independent transrepression complexes. They can also provoke the expression of I $\mathrm{B} \alpha \alpha$ and hold NF- $\kappa$ B in the cytoplasm ${ }^{[17]}$. 
- Anti-oxidants derived from natural agents (e.g. green tea) that inhibit I $\mathrm{B} \alpha$ degradation provoked by TNF- $\alpha$, and activation of NF- $\kappa B^{[18]}$.

- Proteasome inhibitors (e.g. peptidyl aldehydes and lactacystin) that can effectively block ubiquitindependent protein degradation through their ability to inhibit $\mathrm{I} \kappa \mathrm{B} \alpha$ degradation ${ }^{[19]}$.

- Casein kinase-2 inhibitors (e.g. the natural flavone apigenin found in tea, onions, and oranges) that act by stabilizing I $\kappa \mathrm{B} \alpha$ and down-regulating NF- $\kappa \mathrm{B}$ activity ${ }^{[20]}$.

\section{Signaling pathways of NF- $\kappa B$ in parasites}

It is well documented that NF- $\kappa \mathrm{B}$ proteins are nearly expressed by all cells, and are implicated in lymphocytes development, maturation, proliferation as well as survival. Moreover, the expression of variable genes types is coordinated by NF- $\kappa \mathrm{B}$. These genes have crucial roles in host innate and adaptive immune responses, and are strongly associated with inhibition of apoptosis. Interestingly, parasites attack various NF- $\kappa B$ pathway steps, leading to interference with the activity of genes responsible for the immune response. The biology of the different parasites is pivotal in controlling the patterns and kinetics of NF- $\mathrm{KB}$ activity and hence the subsequent immune responses ${ }^{[4]}$.

\section{Protozoa}

\section{Entamoeba histolytica}

In RAW 264.7 cells culture, Gal-lectin caused timeand concentration-dependent elevated expression of mRNA levels of TLR2, and induced NF- $\mathrm{KB}$ p50 and p65 nuclear translocation. The use of SN50 (a specific cell-permeable NF- $\kappa$ B inhibitory peptide), pyrrolidine dithiocarbamate (PDTC), and SB 208530 (to inhibit p38 activity) reduced the expression of TLR-2. Inhibition of mitogen-activated protein kinase (MAPK) activity through SB203580 (p38 kinase specific inhibitor) caused significant reduction of Gal-lectin-induced TLR-2 mRNA induction ${ }^{[21]}$. These findings point to the potential importance of targeting TLR to limit pathological changes in the intestine in response to entamoebiasis histolytica ${ }^{[21]}$.

In addition, the effects of $E$. histolytica Gal-lectin on DCs in mice was investigated in 2007 by Ivory and Chadee ${ }^{[22]}$, who documented that Gal-lectin induced DCs maturation, and up-regulated MHC class II and maturation markers (CD40, CD80, and CD86), besides increasing mRNA levels of IL-12. They also reported that Gal-lectin caused NF- $\kappa B$ p65 nuclear translocation, as well as extracellular signal regulated protein kinase 1 and 2 (ERK 1/2), JNK, and p38 phosphorylation. In spite of stimulating NF- $\kappa B$ p65 activity, the valuable effects of Gal-lectin on DCs maturation could be exploited as a lead molecule for vaccine development $t^{[22]}$.

In 2010, Cho et al. ${ }^{[23]}$ investigated NF-kB p50 subunit activity in murine amoebiasis and reported that its selective deletion in mice increased their susceptibility to infection. This finding reflects that NF- $\kappa \mathrm{B}$ activity, especially activity of the p50 subunit, is partially responsible for rapid clearance and resistance to E. histolytica infection. The use of calpeptin (calpain inhibitor) inhibited degradation of Entamoeba-induced NF- $\kappa \mathrm{B}$, signal transducer and activator of transcription 3 and 5 (STAT3 and STAT5). Degradation of NF- $\mathrm{KB}$ by cysteine protease was found to hasten cell death ${ }^{[24]}$.

In human monocytes, NF- $\kappa \mathrm{B}$ pathway operates through monocyte locomotion inhibitory factor (MLIF). This oligopeptide is heat-stable, detected in Entamoeba axenic cultures, and was documented to contribute to late inflammation in amoebic liver abscess by inhibiting amoebic motility. Furthermore, it prevents the synthesis of adapter protein myeloid differentiation factor 88 (MyD88), increases p50/p50 homo-dimer translocation, and alters translocation and dynamics of p65/p50 heterodimer. In addition, this factor possesses specific anti-inflammatory activities in both in vivo and in vitro models. It inhibits respiratory burst and human monocyte locomotion in neutrophils and monocytes, inhibits vascular cell adhesion molecule- 1 and very late antigen-4 (VLA-4) expression, and increases antiinflammatory cytokines expression ${ }^{[25,26]}$. Activity of MLIF manifests clinically as less invasive intestinal amoebiasis (produced by less virulent strains) ${ }^{[27]}$, and it is not secreted by commensal E. dispar ${ }^{[28]}$. Protective effects of MLIF have been demonstrated in rats, where it reduced cellular inflammatory infiltrate and significantly reduced inflammatory cytokines levels in contused tibia ${ }^{[29]}$. It also protects mice against cerebral malaria ${ }^{[30]}$. Based on most represented studies, it is worth mentioning that the gut epithelial cells exhibit a unique feature in E. histolytica infection, where NF- $\mathrm{kB}$ activity is associated with a healing response, not a proinflammatory one $\mathrm{e}^{[31]}$.

\section{Giardia Iamblia}

In 2012, Lee et $a .^{[32]}$ evaluated the signaling sequences following in vitro incubation of HT-29 gastrointestinal cell line with G. lamblia trophozoites; WB and GS strains that belong to assemblages $A$ and $B$, respectively[33]. They demonstrated increased levels of TNF- $\alpha$, IL-1 $\beta$, and IL-8 (with higher levels in GS-infected cells). The researchers ${ }^{[32]}$ also proved that G. lamblia excretory-secretory products (ESPs) induced IL-8 production by provoking signaling activities of mitogen-activated protein kinases; p38 and extracellular signal regulated protein kinase 1 and 2 , besides activator protein -1 , and NF- $\kappa$ B. They also reported reduced IL-8 levels in response to the use of SB202190 (a p38 specific inhibitor) or inhibiting ERK1/2 activity by PD98059 ${ }^{[32]}$

Giardia lamblia significantly inhibited inducible nitric oxide synthase (iNOS) and cyclooxygenase-2 (COX-2) expression, and nitric oxide (NO) production 
in in vitro cultured LPS-stimulated RAW 264.7 cells or human monocyte-derived macrophages. These mechanisms help Giardia evade the host immune response. Moreover, G. lamblia cleaved the p65 subunit

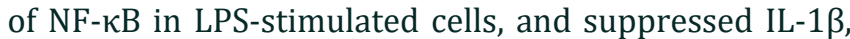
IL-6, and IL-10 expression. These effects were attributed to Giardia proteases; two cysteine proteases and a metalloprotease ${ }^{[34]}$.

\section{Cryptosporidium parvum}

In biliary epithelial cell cultures formed of human bile duct epithelial cells transformed by simian virus 40 (SV40), C. parvum triggered NF- $\kappa \mathrm{B}$ signaling, and increased IL-8 level. Infection also caused NF- $\kappa$ B p50 and p65 nuclear translocation and IкB $\alpha$ degradation. In addition, marked apoptosis was observed in infected cells following inhibition of NF- $\kappa \mathrm{B}$ activity through MG132 (a peptide-aldehyde proteasome inhibitor) or SN50 (a specific cell-permeable NF- $\kappa B$ inhibitory peptide). This finding denotes that anti-apoptotic effects of Cryptosporidium are related to triggering NF- $\mathrm{B}^{[35]}$.

Since C. parvum resides at the apical border of enterocytes with little invasion, epithelial cells innate immunity is crucial for protection of the host. Both NF- $\kappa B$ activity and TLR play important roles in innate immune response against Cryptosporidium ${ }^{[36]}$.

In 2011, O'Hara et al. ${ }^{[37]}$ investigated the role of TLRs4 in C. parvum infection in mice, and documented significant reduction in Cryptosporidium oocysts four weeks post-infection (wpi), and absence of excretion of oocysts in stool three wpi in wild type mice, compared to TLR4-deficient mice. They also reported decline in hepatic IL- 6 and interferon- $\gamma$ (IFN $\gamma$ ) levels at one and two wpi, respectively, in wild type mice. A different pattern was detected in TLR4-deficient mice, where IL-6 and INF- $\gamma$ levels remained high. In addition, they documented reduction in serum liver enzymes (alanine transaminase, aspartate transaminase, and alkaline phosphatase) levels in wild type mice, and persistently high levels in TLR4deficient mice. They also verified the presence of normal histological structure four wpi in wild type mice, whereas TLR4-deficient mice showed severe inflammation in the portal tracts, severe hepatocellular necrosis, and severe proliferation in cholangiocytes. These findings indicate that TLR4 activity can effectively eradicate biliary cryptosporidiosis $^{[37]}$.

\section{Leishmania spp.}

In 2004, Guizani-Tabbane et al. ${ }^{[38]}$ studied the effects of stimulating NF- $\mathrm{KB}$ activation in both fresh human monocytes and promonocytic human cell line U937 infected with L. major. The authors proved that provocation of nuclear translocation of NF-kB p65/p50 complex following phorbol-12 myristate-13 acetate (PMA)-therapy was inhibited by Leishmania in the PMAtreated differentiated U937 cells. They also documented that the expression of NF- $\kappa \mathrm{B}$ complexes (containing $\mathrm{p} 50$ - and c-Rel) was activated in fresh human monocytes and U937 cells. In addition, reduced Leishmania-provoked IL-10 and TNF- $\alpha$ - production in differentiated U937 cells, in response to caffeic acid phenethyl ester (CAPE) used to suppress NF- $\kappa B$ activity was demonstrated ${ }^{[38]}$.

Cutaneous leishmaniasis is associated with a powerful healing response as a result of a robust Th1 immune response in vertebrates. In L. major-infected human DCs, IL-12 was found to be up-regulated, compared to $L$. donovani which does not provoke IL12 production; because induction of IL-12 production differs based on Leishmania species and $\operatorname{strain}^{[39]}$. In 2008, Jayakumar et al. ${ }^{[40]}$ studied the molecular events underlying IL-12 induction in human DCs infected with L. major NIH Friedlin V1 (MHOM/IL/80/FN) strain and L. donovani strain 9515 (MHOM/IN/95/9515). The authors reported significant up-regulation of the levels of IL-12 p35 and IL-12 p40, as well as progressive increase in interferon regulatory factor-1 (IRF-1) and factor-8 (IRF-8) mRNA levels in DCs infected with L. major, compared to DCs infected with L. donovani. Moreover, they detected increased nuclear translocation of NF- $\kappa \mathrm{B}$ p65, NF- $\kappa \mathrm{B}$ p50, c-Rel, IRF-1, and IRF-8, following L. major infection, in comparison with cells infected with $L$. donovani. Jayakumar et al. ${ }^{[40]}$ also documented up-regulation of guanylate binding proteins-1 and -2 (GBP-1 and GBP-2), as well as cyclooxygenase- 2 genes. These genes were observed to be up-regulated in response to L. major infection ${ }^{[11,42]}$. These findings are associated with up-regulation of IL-12 levels that will manifest as a powerful healing response. In addition, Jayakumar et al. ${ }^{[40]}$ reported that inhibition of NF- $\kappa \mathrm{B}$ activation by pre-treatment of DCs using caffeic acid phenethyl ester significantly reduced the mRNA levels of IL-12 p35, IL-12 p40, IRF-1, and IRF-8 in treated DCs infected with L. major, compared to infected untreated cells.

Regarding L. amazonensis, infection proved to be associated with activating $\mathrm{NF}-\kappa \mathrm{B} \mathrm{p} 50 / \mathrm{p} 50$ complex, stimulating the conversion of NF- $\mathrm{kB}$ p65/p50 to NF$\kappa \mathrm{B}$ p50/p50 complex in LPS-activated macrophages, and decreasing p65 levels in infected macrophages. Activation of the NF- $\kappa B$ repressor complex p50/p50 decreases mRNA levels of the iNOS, and NO production in LPS-stimulated macrophages. These effects support the parasite to evade immune attack by the host ${ }^{[43]}$.

\section{Trypanosoma cruzi}

The course of in vitro T. cruzi trypomastigotes (Tulahuen strain) infection in human umbilical vein endothelial cells (HUVEC) culture was studied by Huang et al. ${ }^{[44]}$. They demonstrated that infected TNF$\alpha$-treated HUVEC showed up-regulation of intercellular adhesion molecule-1 (ICAM-1), significant induction of vascular cell adhesion molecule-1 and E-selectin mRNA expression, with persistent elevation of expression of these adhesion molecules in infected cells. They also 
documented NF- $\kappa$ B activation (p50 and p65) in $T$. cruzi-infected HUVEC. According to the researchers, these findings indicate that initiation of $N F-\kappa B$ activity in endothelial cells following T. cruzi infection may contribute to the pathology of chronic Chagas cardiomyopathy, caused by inflammation, subsequent vascular injury, and dysfunction of endothelium.

In 2000, Hall et al. ${ }^{[45]}$ investigated NF- $\kappa B$ signaling in T. cruzi (Silvio, MV13, and Tulahuen strains) cultivated in mink lung epithelial cells (Mv1lu), and demonstrated that trypomastigotes induced DNA binding and nuclear translocation of p65 subunit, and NF- $\kappa B$-dependent gene expression. In addition, trypomastigotes activated nuclear translocation of NF- $\kappa \mathrm{B}$ of human fibroblasts and murine endothelial cells SVEC4-10 in vitro, but did not activate NF- $\mathrm{BB}$ or stimulate p65 translocation in muscle-derived cells (primary cultures of bovine or human smooth muscle cells, rat cardiac myoblast line H9C2, or rat skeletal muscle myoblast line L6E9) ${ }^{[45]}$.

The signaling events underlying T. cruzi (Y strain)induced cardiomyocyte hypertrophy were studied by Petersen et al. ${ }^{[46]}$ who documented that NF- $\kappa B$ is implicated in cardiomyocyte hypertrophy and IL-1 $\beta$ production provoked by T. cruzi. They reported that $T$. cruzi trypomastigotes significantly increased the mean cell size in rat neonatal cardiomyocytes, and that pretreatment of cardiomyocytes with SN50 prevented hypertrophy in $T$. cruzi-infected cells; implying that NF- $\kappa B$ signaling is needed for T. cruzi-induced cardiomyocyte hypertrophy. They also demonstrated completely inhibited hypertrophy in cardiomyocytes pre-treated with TLR2 antibodies; while antibodies to TLR4- did not inhibit T. cruzi-induced hypertrophy. Besides, they documented increased IL-1 $\beta$ production in T. cruzi-infected cardiomyocytes and its reduction in response to TLR2-blocking antibody, increased activation of NF- $\kappa B$ reporter in cells infected with $T$. cruzi, and reduced reporter activation in cardiomyocyte cultures pre-treated with TLR2-blocking antibody ${ }^{[46]}$.

In Chagas' disease, cardiomyocyte apoptosis is a critical determinant of the course of the disease. The host apoptotic pathways in T. cruzi (Y strain) infection differ according to the cell type, i.e., T. cruzi-infected cardiomyocytes and neuronal cells were protected from apoptosis, whereas $\mathrm{T}$ cells showed activated apoptotic response in cardiomyocytes infected with T. cruzi. In vitro protection of cardiomyocytes against apoptosis was elicited by TNF- $\alpha$. The decrease in TNF- $\alpha$ serum levels was correlated to both parasite burden and stimulation of NF- $\kappa \mathrm{B}$ activity. In addition, inhibition of apoptosis diminished activation of caspase-3 (central mediator of apoptosis). Inhibition of apoptosis in $T$. cruzi-infected cardiomyocytes is probably a key event in maintaining infection of the cardiac muscles with diminishing tissue injury, and in apoptosis-concomitant cardiomyocyte reorganization $^{[47]}$.
In 2011, Pinto et al. ${ }^{[48]}$ archived that TNF treatment significantly increased the susceptibility of two epithelial cell lines (LLC-MK2 cells and HEK293T) to infection by T. cruzi (Y strain) in a concentrationdependent manner. It also increased cells susceptibility to trypanosomiasis after exposure to supernatants from T. cruzi-infected human monocytes (phorbol myristate acetate-differentiated). The use of monoclonal antibody to TNF and TPCK (a NF- $\kappa B$ inhibitor) significantly reduced parasite burden.

\section{Trichomonas vaginalis}

Incubation of T. vaginalis (lysates, opsonized-live, and live) with human monocyte-derived macrophages (HMDM) increased NF- $\mathrm{KB}$ p65 nuclear translocation and phosphorylation, and increased the levels of IL-1 $\beta$, IL-6, and TNF- $\alpha$. Furthermore, live T. vaginalis markedly increased generation of NO and expression of iNOS levels in HMDM. The use of the NO synthase inhibitor L-NMMA significantly inhibited NF- $\kappa$ B activation and TNF- $\alpha$ production induced by trichomonads in macrophages. Pre-treatment with pyrrolidine dithiocarbamate or Bay11-7082 (NF- $\kappa B$ inhibitor) decreased TNF- $\alpha$ produced from human macrophages. These findings indicate that TNF- $\alpha$, NO, IL- 1 , and IL- 6 are released by macrophages in response to $T$. vaginalis infection, and that TNF- $\alpha$ production in macrophages is dependent on NO-dependent activation of NF- $\kappa \mathrm{B}$. These events might be implicated in inflammation caused by T. vaginalis $^{[49]}$.

\section{Toxoplasma gondii}

Toxoplasma gondii-infected HeLa cells showed provoked NF- $\kappa$ B signaling activity, and increased mRNA expression of monocyte chemotactic protein-1 (MCP1) and IL-8. The use of calpain-1 inhibitor to inhibit NF- $\kappa B$ signaling significantly decreased Toxoplasmaprovoked MCP-1 and IL- 8 secretion. This implies that NF- $\kappa B$ masters chemokine activity in cells infected with T. gondii, and that the pathogenic effects of T. gondii are related to MCP-1 and IL- 8 secretion, as well as the subsequent staffing of monocytes, neutrophils, and lymphocytes ${ }^{[50]}$.

Shapira et $a l^{[51]}$ investigated the effects of toxoplasmosis both in vivo and in vitro on NF- $\mathrm{\kappa B}$ activity. Markedly increased levels of its binding complexes (mainly p50 and p65) were demonstrated in peritoneal cells from $T$. gondii RH strain-infected mice, compared to uninfected mice. In addition, a significant increase in $\mathrm{NF}-\kappa \mathrm{B}$ (mainly p50) level was recorded denoting that in vivo toxoplasmosis activates NF- $\mathrm{KB}$ signaling. They also demonstrated cytoplasmic localization of NF-kB p65 and c-Rel in unstimulated bone marrow (BM)derived macrophages, and in LPS-stimulated cells; and the absence of p65 or c-Rel signaling in T. gondii RH tachyzoites-infected cells. Besides, they documented activation of p65 in BM-derived macrophages exposed only to LPS, and no response in cells cultured 
with tachyzoites in response to LPS, implying that infection with Toxoplasma can dynamically influence the sequences causing $\mathrm{NF}-\kappa \mathrm{B}$ nuclear translocation following pro-inflammatory stimuli ${ }^{[51]}$.

The signaling activity of NF- $\mathrm{KB}$ and apoptotic cascade-implicated genes expression in murine embryonic fibroblasts (MEFs; wild-type) infected with T. gondii (RH strain) were studied by Molestina et $a l^{[52]}$. They reported p65 and p50 nuclear translocation in infected MEFs after TNF stimulation, compared to uninfected cells that did not display nuclear localization of the two subunits. They also reported provoked phosphorylation of $I \kappa B$, and its recruitment on the parasitophorous vacuole membrane, signifying a direct Toxoplasma effect that could be related to indigenous agents modulating the host NF- $\kappa \mathrm{B}$ activity to guard parasite viability ${ }^{[52]}$. The investigators also documented different patterns of gene expression in wild-type and $\mathrm{p} 65^{-/-}$MEFs following infection with $T$. gondii. Increased anti-apoptotic proteins Bcl-XL and Bfl-1 expression was demonstrated in wild-type MEFs, in comparison with $\mathrm{p} 65^{-/-}$MEFs. Moreover, infected wild-type MEF displayed increases in the expression of inhibitors of apoptosis-1 and -2 (IAP1 and IAP2), and neuronal apoptosis inhibitory protein-1 (NAIP$1)$, compared to $\mathrm{p} 65^{-/-}$cells. These results suggested that anti-apoptotic genes up-regulation is provoked by activated NF- $\kappa B$ signaling, and can manifest clinically as enhanced survival of Toxoplasma ${ }^{[52]}$.

In 2005, Shapira et $a l^{[53]}$ evaluated the impact of Toxoplasma tachyzoites infection on NF- $\mathrm{BB}$-induced TNF- $\alpha$ and IL-12 expression in human foreskin fibroblasts (HFF) and found no nuclear accumulation of p65/RelA in infected cells. They also demonstrated marked IKK activity and I $\mathrm{KB} \alpha$ degradation in $T$. gondii-infected cells, besides markedly delayed I $\mathrm{KB} \alpha$ synthesis. In addition, the authors reported that interrupting proteins nuclear transport mediated by chromosomal region maintenance-1 (CRM1) using leptomicyne $\mathrm{B}$ (LMB) was accompanied with NF$\kappa B$ nuclear accumulation in cells (infected and noninfected). The authors concluded that this indicates that NF- $\mathrm{KB}$ dimers nucleo-cytoplasmic transportation in unstimulated cells is not affected by T. gondii.

Toxoplasma rhoptry protein 18 (ROP18) was documented to interact with p65 subunit of NF- $\mathrm{kB}$ and mediate its proteasome-ubiquitin-dependent degradation that is ROP18 kinase-dependent ${ }^{[54]}$. These authors found that RAW 264.7 cultured cells expressing ROP18-WT (wild-type ROP18 RH strain) had low TNF- $\alpha$, IL-6, and IL-12 p40 levels, compared to kinase-deficient ROP18 RH strain. Also, U937 cells expressing ROP18-WT RH suppressed LPS-induced cytokine production, compared to cells infected with kinase-deficient ROP18 RH strain. These findings

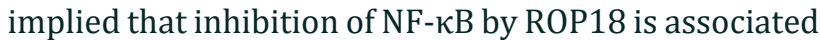

with reduced levels of pro-inflammatory cytokines, which favors Toxoplasma persistence ${ }^{[54]}$.

\section{Plasmodium spp.}

Transfer of the circumsporozoite protein (CSP) from the parasitophorous vacuole to the hepatic cytoplasm was recorded as vital for sporozoites development during exo-erythrocytic cycle of Plasmodium, owing to its blocking effect on NF- $\kappa \mathrm{B}$ activation in hepatocytes. This protein acts by down-regulating the expression of many genes controlled by NF- $\mathrm{BB}$ (inflammationimplicated genes), and by affecting the expression of host genes accountable for different metabolic processes to create a suitable milieu for parasite growth ${ }^{[55]}$.

In 2018, Deng et al. ${ }^{[56]}$ studied the effects of CSP as a potential NF- $\kappa B$ inhibitor on the growth of the human lung cancer cell line A549, and reported suppressed proliferation and induced apoptosis of its cells, following transfection with a recombinant plasmid expressing CSP. The suppressed TNF- $\alpha$-induced activation in response to both CSP and its nuclear localization signal (NLS) motif, markedly inhibited NF$\kappa \mathrm{B}$ nuclear translocation in A549 cells stimulated with TNF- $\alpha$.

The pathogenesis of cerebral malaria (CM) in $P$. falciparum-infected patients involves cytokines release and microvascular sequestration of parasitized $\mathrm{RBCs}^{[57]}$, in addition to signaling factors, such as NF$\kappa \mathrm{B}^{[58]}$. Punsawad et al. ${ }^{[59]}$ investigated NF- $\kappa \mathrm{B}$ p65 and cleaved caspase-3 expression and their association with apoptosis in brain tissues specimens from patients with $\mathrm{CM}$ and non-cerebral malaria (NCM), and normal brains (deceased persons in accidents with no head insult). They recorded positive NF- $\kappa B$ p65 nuclear staining (activated NF- $\kappa \mathrm{B}$ ) in glial cells of the white matter, and in areas with brain injury (Durck's granuloma; reactive gliosis that closely looks like granulomas, and areas of ring haemorrhage). The presence of significant positive correlations between neuronal NF- $\kappa \mathrm{B}$ p65-expression and the total score for histopathological changes was also documented. This indicated that the histopathological changes in $\mathrm{CM}$ are moderated by signaling through p65 subunit of NF$\kappa \mathrm{B}^{[59]}$. In addition, they detected an intense NF- $\kappa \mathrm{B}$ p65 nuclear immunoreactivity in vascular ECs, as well as in circulating inflammatory cells (especially lymphocytes) in cases with CM. Besides, the higher nuclear NF- $\kappa B$ p65 immunoreactivity in intravascular lymphocytes, compared to NCM and controls denoted an active state during malaria infection ${ }^{[59]}$. Significant positive correlations between ECs apoptotic index and nuclear ECs NF- $\kappa B$ index, and between leukocyte apoptotic index and intravascular leukocyte NF- $\mathrm{KB}$ index in $\mathrm{CM}$ brains were verified. These findings conferred that apoptotic changes in intravascular leukocytes and ECs in $\mathrm{CM}$ are potentiated by $\mathrm{NF}-\kappa \mathrm{B}$ p65 signaling ${ }^{[59]}$. 
Expression of glial and neuronal NF- $\kappa$ B p65 and caspase-3 had no association with age, leucocyte count, anemia, hospitalization, last parasite count, and time to death $^{[59]}$.

The expression of NF- $\mathrm{KB}$ and apoptosis in severe falciparum malaria were studied by Viriyavejakul et $a l^{[60]}$ in liver tissues from patients who had died with associated hyperbilirubinaemia, and those without hyperbilirubinaemia, compared to patients who had died from accidents. They reported significantly higher expression of cleaved caspase- 3 in lymphocytes and Kupffer cells in the non-hyperbilirubinaemia group, compared to the normal controls, as well as significantly increased lymphocytes and Kupffer cells apoptosis, and lymphocytes and Kupffer cells NF-kB p65 expression. Besides, they recorded presence of significant positive correlation between NF-kB p65 and cleaved caspase- 3 expression in portal lymphocytes and Kupffer cells. A significant positive correlation was also demonstrated between NF- $\mathrm{BB}$ p65 and cleaved caspase- 3 expression with total bilirubin in lymphocytes and Kupffer cells. Additionally, the expressions of NF-kB p65 and cleaved caspase- 3 were verified to positively correlate with hyperplastic Kupffer cells. The score of portal tract inflammation also showed significant positive correlation with the expression of NF- $\kappa \mathrm{B}$ p 65 and cleaved caspase-3. Non-significant associations were documented between age, gender, duration of pyrexia before hospitalization, liver function tests, and level of parasitaemia, and both portal lymphocytes and Kupffer cells expression of cleaved caspase- 3 and NF- $\kappa$ B p65 $5^{[60]}$.

\section{Theileria parva}

In cattle, T. parva replicates in the cytoplasm of lymphocytes, induces lymphoblastoid transformation, and causes clonal expansion of the infected cell. This autocrine growth caused by induced expression of IL-2 and IL-2 receptor because of the persistent translocation of NF- $\kappa B$ to the nucleus, can be reversed by eradicating the parasite ${ }^{[61]}$. In $T$. parva-infected cloned bovine $\mathrm{T}$ cells, higher I $\mathrm{I} B \alpha$ levels and lower I $\mathrm{B} \beta$ levels were detected, compared to uninfected cells, in

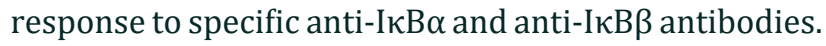
Theileria provoked continuous degradation of both I $\kappa \mathrm{B} \alpha$ and $\mathrm{I} \kappa \mathrm{B} \beta . \mathrm{I} \kappa \mathrm{B} \alpha$ re-accumulated to high levels in infected cells, denoting that T. parva did not affect the normal NF- $\kappa \mathrm{B}$-mediated positive feedback loop, while maintaining low cytoplasmic I $\kappa B \beta$ levels. The use of BW720c (a hydronaphthoquinone derivative lethal to $T$. parva) restored normal IкB $\beta$ levels. In addition, treatment of T. parva-infected cells with pyrrolidine dithiocarbamate inhibited I $\mathrm{B}$ degradation, in contrast to the anti-oxidant $\mathrm{N}$-acetylcysteine that showed no effect on IKB levels or NF- $\kappa B$ activation ${ }^{[62]}$.

\section{Helminths \\ Fasciola hepatica}

Hamilton et al. ${ }^{[63]}$ studied the effects of $F$. hepatica tegumental antigen on the activation and function of
DCs in mice, and reported that the antigen significantly suppressed nitrite, TNF- $\alpha$, IL-6, IL-10, and IL-12 p70 levels, and the expression of cell surface marker of CD40, CD80, and CD86 in DCs matured with TLR and non-TLR ligands. They also documented suppression of NF- $\kappa \mathrm{B}$ p65 in mature DCs, which can justify the reduction in pro-inflammatory cytokine levels, implying that the tegumental antigen of $F$. hepatica has potent antiinflammatory activities and a possible beneficial effect as an anti-inflammatory component ${ }^{[63]}$.

\section{Clonorchis sinensis}

Previous studies reported that contact of C. sinensis adult parasites and their ESPs with bile ducts and adjacent hepatic tissues, as well as the subsequent oxidative stress and chronic inflammation aggravate epithelial hyperplasia, periductal fibrosis, and cholangiocarcinogenesis ${ }^{[64,65]}$. Pak et $a l^{[66]}$ investigated two redox-active proteins induced by ESPs; peroxiredoxin 6 (Prdx6) and NF$\kappa B$, in murine clonorchiasis. The authors reported that in ESPs-treated cholangiocarcinoma cells, the generation of intracellular free-radicals was inhibited by overexpression of Prdx6 through inhibition of iNOS and NADPH oxidase 2, significantly decreasing inflammation; and that overexpression of NF- $\mathrm{KB}$ suppressed Prdx6 transcription levels. They also demonstrated that immunoreactive NF- $\kappa B$ and Prdx6 distribution was more marked in the liver in initial infection stages, and that their immunopositive staining extent and intensity in infected mice correlates with both duration and severity of infection. These findings suggest that the increased levels of NF- $\kappa \mathrm{B}$ and Prdx6 in clonorchiasis are linked to massive histopathological changes $^{[66]}$.

Using cholangiocarcinoma cell lines, Pak et al. ${ }^{[67]}$ investigated the effects of ESPs on cellular migration and invasion, and documented significantly increased concentration-dependent expression and activity of matrix metalloproteinase-9 (MMP-9) enzymes through augmented NF- $\mathrm{B}$ s signaling. Besides, ESPs induced $\mathrm{I} \kappa \mathrm{B} \alpha$ degradation and phosphorylation, and provoked nuclear translocation of NF- $\kappa \mathrm{B}$ p65, controlled by extracellular signal regulated protein kinase 1 and 2 activity. These findings denote that both ESPs-provoked MMP-9 activity and stimulated NF- $\kappa \mathrm{B}$ and $I \kappa \mathrm{B} \alpha$ are associated with a progressive course of cholangiocarcinoma ${ }^{[67]}$; since MMP-9, which is involved in the degradation of the extracellular matrix, is wellrecognized to have a principle effect on invasion of malignant cells and metastasis ${ }^{[68]}$.

\section{Opisthorchis viverrini}

Infection with $O$. viverrini elicits inflammationmediated oxidative and nitrosative DNA damage, which predisposes to the development of cholangiocarcinoma $^{[69]}$. In 2005, Pinlaor et al. ${ }^{[70]}$ evaluated the effects of an 0 . viverrini-derived antigen on expression of TLRs using RAW 264.7 macrophage 
cell line, and reported that the antigen provoked TLR2 expression. They also documented dose-dependent expression of NF- $\kappa \mathrm{B}$, cyclooxygenase-2, and iNOS, in RAW 264.7 cells, in response to 0 . viverrini antigen.

In 2006, Pinlaor et al. ${ }^{[71]}$ investigated the preventive effect of the anti-helminthic drug praziquantel (PZQ) on 8-nitroguanine and 8-oxo-7,8-dihydro2 '-deoxyguanosine (8-oxodG) formation, and iNOS expression in hamsters infected with 0 . viverrini. Apparently, the PZQ treatment did not totally eradicate the parasites, but markedly decreased inflammatory cell infiltration, totally reduced 0 . viverrini-provoked production of 8-nitroguanine and 8-oxodG in biliary cells, and significantly decreased hepatic 8-oxodG level in biliary epithelium. There was an associated reduced NF- $\mathrm{BB}$ and iNOS expression in biliary cells, and significantly decreased levels of nitrite and nitrate in plasma and liver of 0 . viverrini-infected treated hamsters, compared to controls.

In 2010, Laothong et $a l^{[72]}$ documented that melatonin can guard against cholangiocarcinoma provoked by Opithorchis infection, through decreasing nitrosative and oxidative DNA damage through initiating the activity of erythroid 2-related factor 2 (Nrf2), as well as inhibiting NF- $\kappa \mathrm{B}$ activity. The authors studied the protective effects of oral melatonin and reported decreased levels of 8-nitroguanine and 8-oxodG in inflammatory cells and biliary epithelium, and 3-nitrotyrosine in the liver, and decreased levels of nitrate/nitrite, and cytokeratin 19 (CK-19; used as a marker to assess proliferation of bile ducts) and heme oxygenase- 1 expression, in hamsters infected with $O$. viverrini. In addition, they documented dose-dependent decreases in alanine transaminase, 8-isoprostane, and vitamin E levels in plasma, and in nitrate/nitrite level in liver homogenates, in melatonin-treated hamsters. Besides, IL-1 $\beta$, TNF- $\alpha$, and oxidant-generating genes (NF- $\kappa \mathrm{B}$, cyclooxygenase-2, and iNOS) showed dosedependent reductions in mRNA expression, in treated hamsters. They also demonstrated a dose-dependent increased expression of anti-oxidant genes (erythroid 2-related factor 2 and manganese superoxide dismutase), compared to 0 . viverrini-infected untreated hamsters.

\section{Schistosoma spp.}

In 2015, Ashour et al. ${ }^{[73]}$ studied NF- $\kappa \mathrm{B}$ activity in murine colonic schistosomiasis mansoni and documented marked increase in TLR2 expression and NF- $\kappa B$ positive cells in all colonic cells, granulomas, and lymphoid follicles, compared to uninfected mice; and recommended that TLR2 and NF- $\kappa B$ could be targeted to treat colonic schistosomiasis.

The effect of genistein on inhibiting the activity of NF-кB in S. japonicum hepatic granuloma and fibrosis was evaluated by Wan et al. ${ }^{[74]}$ who demonstrated amelioration of liver pathology. This included regression of granulomatous inflammation, inhibited mRNA expression of NF- $\kappa$ B p65, I $\mathrm{B}-\alpha$, TNF- $\alpha$, monocyte chemotactic protein-1, IL-1 $\beta$, IL-4, and IL-10 in liver tissue during early phase of infection. Significant reductions in the contents of transforming growth factor- $\beta$ (TGF- $\beta$ ) and $\alpha$-smooth muscle actin ( $\alpha$-SMA) in liver tissue in late infection, were also recorded in genistein-treated mice, compared to infected mice.

Besides, the hepatoprotective effects of NF- $\kappa \mathrm{B}$ inhibition on murine schistosomiasis mansoni were investigated by Alhusseiny et al. ${ }^{[75]}$ who evaluated the effects of the NO donor isosorbide-5-mononitrate (IS-5$\mathrm{MN}$ ) and the NF- $\kappa \mathrm{B}$ inhibitor vinpocetine, as adjuvants to praziquantel on murine schistosomiasis mansoni. The authors documented significantly reduced NF- $\mathrm{BB}$ p65 expression following vinpocetine as monotherapy and when combined with IS-5-MN. This NF- $\kappa B$ inhibitory effect partially explained the significantly decreased diameter and count of granulomas, in response to vinpocetine monotherapy ${ }^{[76]}$, as a result of decreased IFN- $\gamma$ activity ${ }^{[77]}$, and decreased TNF and delayed granuloma formation ${ }^{[78]}$, respectively.

\section{Echinococcus spp.}

The role of NF- $\kappa B$ in controlling local and systemic inflammatory and immunological responses in patients with pulmonary hydatidosis either for the first time or in patients with rebound infection was investigated by Tilioua et $a{ }^{\left[{ }^{[79]}\right.}$. The authors studied NF- $\kappa B$ and iNOS expression in peripheral blood mononuclear cells (PBMC) and in peri-cystic layer, and assessed NO and TNF- $\alpha$ in plasma samples. They verified high expression of NF-kB and iNOS in both PBMCs and pericystic histiocytes, as well as elevated NO and TNF- $\alpha$ levels in patients with primary infection. In contrast, they documented reduced expression of NF- $\mathrm{KB}$ and iNOS, and reduced NO and TNF- $\alpha$ levels in patients with rebound hytdatidosis denoting that NF- $\mathrm{KB}$ suppressed activity is associated with defective immune response and helps the parasite evade host immunity in rebound patients $^{[79]}$.

\section{CONCLUDING REMARKS}

1. Data presented here evidently denotes that host NF$\kappa \mathrm{B}$ activation is associated with the development of severe pathology following parasitic infections due to high levels of cytokines and inflammatory mediators.

2.Parasites can manipulate NF- $\kappa \mathrm{B}$; cleavage, degradation, or reduced levels of p65 subunit were verified in response to G. lamblia, T. gondii, and $L$. amazonensis, respectively.

3.Signaling activity of NF- $\kappa B$ was proved to be associated with anti-apoptotic effects in C. parvum and T. gondii.

4. Activation of NF- $\kappa$ B signaling was linked to beneficial consequences in E. histolytica and L. major. 
5. Inhibition of NF- $\kappa$ B activity can alleviate inflammation caused by $T$. vaginalis infection, lymphoblastoid transformation in T. parva, and histopathological changes induced by $S$. japonicum, $S$. mansoni, $C$. sinensis, and $O$. viverrini.

6. Targeting NF- $\kappa B$ signaling pathways could be a promising approach for ameliorating tissue damage caused by the inflammatory mediators, by precise control between harmful and beneficial effects of host NF- $\mathrm{BB}$ activation.

7. Future in-depth studies are crucial to explore the effect of NF- $\kappa B$ activation and inhibition on protozoan and helminthic parasitic infections, and to develop NF- $\kappa$ B cell-specific agents that inhibit NF- $\kappa B$ activity only in target cells, without inducing toxicity or affecting innate immunity.

Author contribution: Alhusseiny, SM conceived the review topic, searched for information, and wrote the manuscript. El-Beshbishi, SN helped in the review design, critically revised the manuscript for intellectual content and approved the final version for publication.

Conflict of interest: None.

Funding statement: None.

\section{REFERENCES}

1. Hayden MS, Ghosh S. Shared principles in NF-kappaB signaling. Cell 2008; 132(3):344-362.

2. Sen R, Baltimore D. Multiple nuclear factors interact with the immunoglobulin enhancer sequences. Cell 1986; 46(5):705-716

3. Napetschnig J, Wu H. Molecular basis of NF- $\mathrm{BB}$ signaling. Annu Rev Biophys 2013; 42:443-468.

4. Symeonidou I, Kourelis A, Frydas, I, Karagouni, E, Anogeianaki A, Hatzistilianou M, et al. Modulation of NFkappa B signalling pathways by parasites. J Biol Regul Homeost Agents 2010; 24(4):471-479.

5. Liu T, Zhang L, Joo D, Sun SC. NF- $\mathrm{BB}$ signaling in inflammation. Signal Transduct Target Ther 2017; 2: 17023 .

6. Oeckinghaus A, Ghosh S. The NF-kappaB family of transcription factors and its regulation. Cold Spring Harb Perspect Biol 2009;1:a000034.

7. Sun SC, Chang JH, Jin J. Regulation of nuclear factorkappaB in autoimmunity. Trends Immunol 2013; 34(6):282-289.

8. Sun SC, Ley SC. New insights into NF-kappaB regulation and function. Trends Immunol 2008; 29(10):469-478.

9. Lindström TM, Bennett PR. The role of nuclear factor kappa B in human labour. Reproduction 2005; 130(5): 569-581.

10. Liou HC. Regulation of the immune system by NF- $\mathrm{kB}$ and IkB. J Biol Chem 2002; 5:537-546.

11. Kawai T, Akira S. Signaling to NF-kappaB by toll-like receptors. Trends Mol Med 2007; 13(11):460-469.

12. Collins T, Williams A, Johnston GI, Kim J, Eddy R, Shows T, et al. Structure and chromosomal location of the gene for endothelial-leukocyte adhesion molecule 1. J Biol Chem 1991; 266(4):2466-2473.

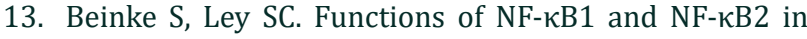
immune cell biology. Biochem J 2004; 382(2):393-409.

14. Kumar A, Takada Y, Boriek AM, Aggarwal BB. Nuclear factor-кB: Its role in health and disease. J Mol Med 2004; 82(7):434-448

15. Yamamoto Y, Gaynor RB. Therapeutic potential of inhibition of the NF- $\mathrm{KB}$ pathway in the treatment of inflammation and cancer. J Clin Invest 2001; 107(2):135142.

16. Yin MJ, Yamamoto Y, Gaynor RB. The anti-inflammatory agents aspirin and salicylate inhibit the activity of I(kappa)B kinase-beta. Nature 1998; 396(6706):77-80.

17. Helmberg A, Auphan N, Caelles C, Karin M. Glucocorticoidinduced apoptosis of human leukemic cells is caused by the repressive function of the glucocorticoid receptor. EMBO J 1995; 14(3):452-460.

18. Ahmad N, Gupta S, Mukhtar H. Green tea polyphenol epigallocatechin-3-gallate differentially modulates nuclear factor kappa B in cancer cells versus normal cells. Arch Biochem Biophys 2000; 376(2):338-346.

19. Sun B, Karin M. NF-kappaB signaling, liver disease and hepatoprotective agents. Oncogene 2008; 27(48): 62286244.

20. Patel D, Shukla S, Gupta S. Apigenin and cancer chemoprevention: Progress, potential and promise. Int J Oncol 2007; 30(1):233-245.

21. Kammanadiminti SJ, Mann BJ, Dutil L, Chadee K. Regulation of toll-like receptor-2 expression by the Gal-lectin of Entamoeba histolytica. FASEB J 2004; 18(1):155-157.

22. Ivory $\mathrm{CP}$, Chadee K. Activation of dendritic cells by the Gal-lectin of Entamoeba histolytica drives Th1 responses in vitro and in vivo. Eur J Immunol 2007; 37(2):385-394.

23. Cho KN, Becker SM, Houpt ER. The NF-kappa B p50 subunit is protective during intestinal Entamoeba histolytica infection of 129 and C57BL/6 mice. Infect Immun 2010; 78(4):1475-1481.

24. Kim KA, Min A, Lee YA, Shin MH. Degradation of the transcription factors NF-KB, STAT3, and STAT5 is involved in Entamoeba histolytica-induced cell death in Caco-2 colonic epithelial cells. Korean J Parasitol 2014; 52(5):459-469.

25. Velazquez JR, Kretschmer RR. Entamoeba histolytica, a remarkable anti-inflammatory parasite. Inmunologia 2004; 23(2):200-206

26. Silva-García R, Rico-Rosillo G. Anti-inflammatory defense mechanisms of Entamoeba histolytica. Inflamm Res 2011; 60(2):111-117.

27. Kretschmer R, Collado ML, Pacheco M, Salinas MC, López-Osuna M, Lecuona $\mathrm{M}$, et al. Inhibition of human monocyte locomotion by products of axenically grown $E$. histolytica. Parasite Immunol 1985; 7(5):527-543.

28. Silva García R, Rico Rosillo G, Espinosa Cantellano M, Castañon G, Giménez Scherer J, Kretschmer R. Entamoeba dispar does not produce monocyte locomotion inhibitory factor (MLIF) produced by Entamoeba histolytica. Parasite Immunol 2003; 25(2):99-101. 
29. Rojas-Dotor S, Araujo-Monsalvo VM, Sánchez-Rojas, MJ, Domínguez-Hernández, VM. The Monocyte locomotion inhibitory factor inhibits the expression of inflammationinduced cytokines following experimental contusion in rat tibia. Scand J Immunol 2018; 88(3):e12702.

30. Galán-Salinas A, Corral-Ruíz G, Pérez-Vega MJ , FabilaCastillo L, Silva-García R, Marquina-Castillo B. Monocyte locomotion inhibitory factor confers neuroprotection and prevents the development of murine cerebral malaria. Int Immunopharmacol 2021; 97:107674.

31. Karrasch T, Jobin C. NF- $\kappa B$ and the intestine: Friend or foe? Inflamm Bowel Dis 2008; 14(1):114-124.

32. Lee H-Y, Hyung S, Lee NY, Yong T-S, Han S-H, Park S-J. Excretory-secretory products of Giardia lamblia induce interleukin-8 production in human colonic cells via activation of p38, ERK1/2, NF- $\mathrm{KB}$ and AP-1. Parasite Immunol 2012; 34(4):183-198.

33. Jerlström-Hultqvist J, Ankarklev J, Svärd SG. Is human giardiasis caused by two different Giardia species? Gut Microbes 2010; 1(6):379-382.

34. Faria CP, Neves BM, Lourenço Á, Cruz MT, Martins JD, Silva A, et al. Giardia lamblia decreases NF-кB p65RelA protein levels and modulates LPS-induced proinflammatory response in macrophages. Sci Rep 2020; 10(1):6234.

35. Chen XM, Levine SA, Splinter PL, Tietz PS, Ganong AL, Jobin C, et al. Cryptosporidium parvum activates nuclear factor kappaB in biliary epithelia preventing epithelial cell apoptosis. Gastroenterology 2001; 120(7):17741783.

36. Zhou R, Hu G, Liu J, Gong A-Y, Drescher KM, Chen X-M. NFkappa B p65-dependent transactivation of miRNA genes following Cryptosporidium parvum infection stimulates epithelial cell immune responses. PLoS Pathog 2009; 5(12):e1000681.

37. O'Hara SP, Bogert PS, Trussoni CE, Chen X, LaRusso NF. TLR4 promotes Cryptosporidium parvum clearance in a mouse model of biliary cryptosporidiosis. J Parasitol 2011; 97(5):813-821.

38. Guizani-Tabbane L, Ben-Aissa K, Belghith M, Sassi A, Dellagi K. Leishmania major amastigotes induce p50/cRel NF- $\kappa B$ transcription factor in human macrophages: Involvement in cytokine synthesis. Infect Immun 2004; 72(5):2582-2589.

39. McDowell MA, Marovich M, Lira R, Braun M, Sacks D. Leishmania priming of human dendritic cells for CD40 ligand-induced interleukin-12p70 secretion is strain and species dependent. Infect Immun 2002; 70(8):39944001.

40. Jayakumar A, Donovan MJ, Tripathi V, Ramalho-Ortigao M, McDowell MA. Leishmania major infection activates NF- $\kappa \mathrm{B}$ and interferon regulatory factors 1 and 8 in human dendritic cells. Infect Immun 2008; 76(5): 21382148.

41. Decker T, Lew DJ, Darnell JE Jr. Two distinct alphainterferon-dependent signal transduction pathways may contribute to activation of transcription of the guanylate-binding protein gene. Mol Cell Biol 1991; 11 (10):5147-5153
42. Vila-del SolV,Fresno M. Involvement of TNF and NF-kappa $\mathrm{B}$ in the transcriptional control of cyclooxygenase-2 expression by IFN-gamma in macrophages. J Immunol 2005; 174(5):2825-2833.

43. Calegari-Silva TC, Pereira RM, De-Melo LD, Saraiva EM, Soares DC, Bellio M, et al. NF-kappaB-mediated repression of iNOS expression in Leishmania amazonensis macrophage infection. Immunol Lett 2009; 127(1):19-26.

44. Huang $\mathrm{H}$, Calderon TM, Berman JW, Braunstein VL, Weiss LM, Wittner M, et al. Infection of endothelial cells with Trypanosoma cruzi activates NF-kappa B and induces vascular adhesion molecule expression. Infect Immun 1999; 67(10):5434-5440.

45. Hall BS, Tam W, Sen R, Pereira ME. Cell-specific activation of nuclear factor-kappa B by the parasite Trypanosoma cruzi promotes resistance to intracellular infection. Mol Biol Cell 2000; 11(1):153-160.

46. Petersen CA, Krumholz KA, Burleigh BA. Toll-like receptor 2 regulates interleukin-1 $\beta$-dependent cardiomyocyte hypertrophy triggered by Trypanosoma cruzi. Infect Immun 2005; 73(10):6974-6980.

47. Petersen CA, Krumholz KA, Carmen J, Sinai AP, Burleigh BA. Trypanosoma cruzi infection and nuclear factor kappa B activation prevent apoptosis in cardiac cells. Infect Immun 2006; 74(3):1580-1587.

48. Pinto AM, Sales PC, Camargos ER, Silva AM. Tumour necrosis factor (TNF)-mediated NF- $\mathrm{KB}$ activation facilitates cellular invasion of non-professional phagocytic epithelial cell lines by Trypanosoma cruzi. Cell Microbiol 2011; 13(10):1518-1529.

49. Han IH, Goo SY, Park SJ, Hwang SJ, Kim YS, Yang MS, et al. Proinflammatory cytokine and nitric oxide production by human macrophages stimulated with Trichomonas vaginalis. Korean J Parasitol 2009; 47(3):205-212.

50. Kim JM, Oh YK, Kim YJ, Cho SJ, Ahn MH, Cho YJ. Nuclear factor-kappa B plays a major role in the regulation of chemokine expression of $\mathrm{HeLa}$ cells in response to Toxoplasma gondii infection. Parasitol Res 2001; 87(9):758-763.

51. Shapira S, Speirs K, Gerstein A, Caamano J, Hunter CA. Suppression of NF-kappa B activation by infection with Toxoplasma gondii. J Infect Dis 2002; 185(S1):S66-72.

52. Molestina RE, Payne TM, Coppens I, Sinai AP. Activation of NF-kappaB by Toxoplasma gondii correlates with increased expression of antiapoptotic genes and localization of phosphorylated I kappa B to the parasitophorous vacuole membrane. J Cell Sci 2003; 116(21):4359-4371.

53. Shapira S, Harb OS, Margarit J, Matrajt M, Han J, Hoffmann A, et al. Initiation and termination of NFkappa B signaling by the intracellular protozoan parasite Toxoplasma gondii. J Cell Sci 2005; 118(15):3501-3508.

54. Du J,An R, Chen L, Shen Y, Chen Y, Cheng L. Toxoplasma gondii virulence factor ROP18 inhibits the host NF- $\kappa \mathrm{B}$ pathway by promoting p65 degradation. J Biol Chem 2014; 289(18):12578-12592.

55. Singh AP, Buscaglia CA, Wang Q Levay A, Nussenzweig DR, Walker JR, et al. Plasmodium circumsporozoite 
protein promotes the development of the liver stages of the parasite. Cell 2007; 131(3):492-504.

56. Deng XF, Zhou D, Liu QX, Zheng H, Ding Y, Xu WY, et al. Plasmodium circumsporozoite protein suppresses the growth of A549 cells via inhibiting nuclear transcription factor $\kappa$ B. Oncol Lett 2018; 15(5):6585-6591.

57. Craig AG, Khairul MF, Patil PR. Cytoadherence and severe malaria. Malays J Med Sci 2012; 19(2):5-18.

58. Tripathi AK, Sha W, Shulaev V, Stins MF, Sullivan DJ Jr. Plasmodium falciparum-infected erythrocytes induce NF-kappa B regulated inflammatory pathways in human cerebral endothelium. Blood 2009; 114(19):4243-4252.

59. Punsawad C, Maneerat Y, Chaisri U, Nantavisai K, Viriyavejakul P. Nuclear factor kappa B modulates apoptosis in the brain endothelial cells and intravascular leukocytes of fatal cerebral malaria. Malaria J 2013; 12:260.

60. Viriyavejakul P, Khachonsaksumet V, Punsawad C. Liver changes in severe Plasmodium falciparum malaria: Histopathology, apoptosis and nuclear factor kappa B expression. Malaria J 2014; 13:106.

61. Dobbelaere DA. Fernandez PC, Heussler VT. Theileria parva: Taking control of host cell proliferation and survival mechanisms. Cell Microbiol 2000; 2(2):91-99.

62. Palmer GH, Machado JrJ, Fernandez P, Heussler V, Perinat T, Dobbelaere DA. Parasite-mediated nuclear factor kappa B regulation in lymphoproliferation caused by Theileria parva infection. Proc Natl Acad Sci USA 1997; 94(23):12527-12532.

63. Hamilton CM, Dowling DJ, Loscher CE, Morphew RM, Brophy PM, O'Neill SM. The Fasciola hepatica tegumental antigen suppresses dendritic cell maturation and function. Infect Immun 2009; 77(6):2488-2498.

64. Choi BI, Han JK, Hong ST, Lee KH. Clonorchiasis and cholangiocarcinoma: Etiologic relationship and imaging diagnosis. Clin Microbiol Rev 2004; 17(3):540-552.

65. Lim JH. Liver flukes: The malady neglected. Korean J Radiol 2011; 12(3):269-279.

66. Pak JH, Son WC, Seo SB, Hong SJ, Sohn WM, Na BK, et al. Peroxiredoxin 6 expression is inversely correlated with nuclear factor- $\mathrm{\kappa B}$ activation during Clonorchis sinensis infestation. Free Radic Biol Med 2016; 99:273-285.

67. Pak JH, Shin J, Song IS, Shim S, Jang SW. Clonorchis sinensis excretory-secretory products regulate migration and invasion in cholangiocarcinoma cells via extracellular signal-regulated kinase $1 / 2 /$ nuclear factor- $\mathrm{B}$ dependent matrix metalloproteinase- 9 expression. Int J Parasitol 2017; 47(1):51-59.

68. Huang H. Matrix metalloproteinase-9 (MMP-9) as a cancer biomarker and MMP-9 biosensors: Recent advances. Sensors 2018; 18(10):3249.

69. Pinlaor S, Hiraku Y, Ma N, Yongvanit P, Semba R, Oikawa S, et al. Mechanism of NO-mediated oxidative and nitrative
DNA damage in hamsters infected with Opisthorchis viverrini: A model of inflammation-mediated carcinogenesis. Nitric Oxide 2004; 11(2):175-183.

70. Pinlaor S, Tada-Oikawa S, Hiraku Y, Pinlaor P, Ma N, Sithithaworn $\mathrm{P}$, et al. Opisthorchis viverrini antigen induces the expression of toll-like receptor 2 in macrophage RAW cell line. Int J Parasitol 2005; 35(6):591-596.

71. Pinlaor S, Hiraku Y, Yongvanit P, Tada-Oikawa S, Ma $\mathrm{N}$, Pinlaor $\mathrm{P}$, et al. iNOS-dependent DNA damage via NF-kappa B expression in hamsters infected with Opisthorchis viverrini and its suppression by the antihelminthic drug praziquantel. Int J Cancer 2006; 119(5):1067-1072.

72. Laothong U, Pinlaor P, Hiraku Y, Boonsiri P, Prakobwong $\mathrm{S}$, Khoontawad J, et al. Protective effect of melatonin against Opisthorchis viverrini-induced oxidative and nitrosative DNA damage and liver injury in hamsters. J Pineal Res 2010; 49(3):271-282.

73. Ashour DS, Shohieb ZS, Sarhan NI. Upregulation of Tolllike receptor 2 and nuclear factor-kappa B expression in experimental colonic schistosomiasis. J Adv Res 2015; 6(6): 877-884.

74. Wan C, Jin F, Du Y, Yang K, Yao L, Mei Z, et al. Genistein improves schistosomiasis liver granuloma and fibrosis via dampening NF-kB signaling in mice. Parasitol Res 2017; 116(4):1165-1174.

75. Alhusseiny SM, El-Beshbishi SN, Abu Hashim MM, ElNemr HE, Handoussa AE. Effectiveness of vinpocetine and isosorbide-5-mononitrate on experimental schistosomiasis mansoni: Biochemical and immunohistochemical study. Acta Trop 2018; 186:1623.

76. Alhusseiny SM, El-Beshbishi SN, Abu Hashim MM, El-Nemr HE, Handoussa AE. A comparative study on the anti-schistosomal and hepatoprotective effects of vinpocetine and isosorbide-5-mononitrate on Schistosoma mansoni-infected mice. Acta Trop 2017; 176:114-125.

77. Rezende SA, Oliveira VR, Silva AM, Alves JB, Goes AM, Reis LF. Mice lacking the gamma interferon receptor have an impaired granulomatous reaction to Schistosoma mansoni infection. Infect Immun 1997; 65(8):34573461.

78. Davies SJ, Lim KC, Blank RB, Kim JH, Lucas KD, Hernandez DC, et al. Involvement of TNF in limiting liver pathology and promoting parasite survival during schistosome infection. Int J Parasitol, 2004; 34(1):27-36.

79. Tilioua S, Mezioug D, Amir-Tidadini ZC, Medjdoub YM, Touil-Boukoffa C. Potential role of NF- $\kappa$ B pathway in the immuno-inflammatory responses during human cystic echinococcosis. Acta Trop 2020; 203:105306. 